\title{
MR Cisternography in the Posterior Fossa: The Evaluation of Trigeminal Neurovascular Compression
}

\author{
Arka Fossada MR Sisternografi: Trigeminal Nörovasküler Kompresyon \\ Değerlendirilmesi
}

\author{
Xiao ANQI ${ }^{1}$, Lei DING ${ }^{1}$, Xiao JIAHE 2 , $\mathrm{Li}_{\text {ZHENLIN }}^{2}$, Xia $\mathrm{CHUNCHAO}^{2}$, You CHAO ${ }^{1}$ \\ ${ }^{1}$ West China Hospital, Sichuan University, Department of Neurosurgery, Chengdu 610041, P. R. China \\ ${ }^{2}$ West China Hospital, Sichuan University, Department of Radiology, Chengdu 610041, P. R. China
}

Correspondence address: Chao YOU / E-mail: youchaost@yahoo.cn

\begin{abstract}
AIM: To evaluate the utility of 3D-magnetic resonance cisternography(MRC) of posterior cranial fossa in visualizing trigeminal neurovascular compression in patients with trigeminal neuralgia.

MATERIAL and METHODS: 146 consecutive patients in the period from June 2010 to July 2011 in our institute diagnosed with trigeminal neuralgia underwent MRC on the posterior cranial fossa. MR devices used for MRC included two sets of 3.0 tesla and one set of 1.5 tesla. The hydrography sequences for MRC included 3D-SPACE and 3D-DRIVE.

RESULTS: In total, 75 patients (51.4\%) were found with trigeminal neurovascular compression on MRC. Among them, 25 patients underwent microvascular decompression. Intraoperatively, 20 patients (80\%) had related arteries consistent with imaging manifestations on MRC. Nevertheless, the arterial compression combined with petrosal vein could not be identified on MRC in 3 of the 20 patients. In the inconsistent 5 cases, the involved vessels were confirmed as superior petrosal veins during the surgery.

CONCLUSION: 3D-MRC has prominent clinical value in determining the trigeminal neurovascular compression and identifying the related vessels. However, MRC does have certain limitations on identifying petrosal vein compression.
\end{abstract}

KEYWORDS: Magnetic resonance cisternography, Trigeminal nerve, Cerebellopontine angle cistern, Neurovascular compression

öz

AMAÇ: Trigeminal nöraljili hastalarda trigeminal nörovasküler kompresyonu görüntülemek açısından posterior kraniyal fossa 3B manyetik rezonans sisternografinin (MRS) faydasını değerlendirmek.

YÖNTEM ve GEREÇLER: Kurumumuzda Haziran 2010 ile Temmuz 2011 arasında trigeminal nöralji tanısı konan arka arkaya 146 hastada posterior kraniyal fossada MRS yapıldı. MRS için kullanılan MR cihazları arasında 3,0 tesla değerinde iki set ve 1,5 tesla değerinde 1 set vardı. MRS hidrografi dizileri arasında 3D-SPACE ve 3D-DRIVE bulunmakta.

BULGULAR: Toplam olarak MRS'de 75 hastada $(\% 51,4)$ trigeminal nörovasküler kompresyon bulundu. Bunlar arasında 25 hastaya mikrovasküler dekompresyon yapıldı. İntraoperatif olarak 20 hastada (\%80) MRS'de görüntüleme bulgularıyla tutarlı ilişkili arterler vardı. Yine de petrosal ven ile kombine arteriyel kompresyon 20 hastanın 3'ünde MRS'de tanımlanamadı. Tutarsız 5 vakada ilgili damarlar cerrahi sırasında superior petrosal venler olarak doğrulandı.

SONUÇ: 3B-MRS'nin trigeminal nörovasküler kompresyonu belirlemek ve ilgili damarları tanımlamakta önemli klinik değeri vardır. Ancak MRS petrosal ven kompresyonunun tanımlamak konusunda belirli sınırlamalara sahiptir.

ANAHTAR SÖZCÜKLER: Manyetik rezonans sisternografi, Trigeminal sinir, Serebelopontin açı sisterni, Nörovasküler kompresyon

\section{INTRODUCTION}

Trigeminal neuralgia caused by vascular compression is commonly seen clinically $(1,3,4,7,20,23,24)$, and accurate diagnosis often depends on the imaging the evidence of trigeminal neurovascular compression (NVC) $(20,23)$. The value of the traditional imaging on diagnosis of NVC is very limited, and conventional MRI is also inadequate to provide precise assessment of nerve-vessel relationship in cerebellopontine angle (CPA) region (19,23). By increasing the contrast between cerebrospinal fluid and vessels/ nerves, MR cisternography (MRC) could clearly display trigeminal nerve root and adjacent vessels to get direct signs of possible NVC (21). To evaluate the clinical significance of 3D-MRC on the demonstration of NVC and offer valuable imaging information of trigeminal neuralgia to neurosurgeons, we reviewed clinical and image data of 146 consecutive patients 
who underwent 3D-MRC due to trigeminal neuralgia in our institute in fourteen months.

\section{MATERIAL and METHODS}

146 consecutive cases with trigeminal neuralgia were examined by MRC in the duration from June 2010 to July 2011 in our institute. The MR devices used for MRC included Trio 3.0T and Avanto 1.5T (Simenz company), and Achieva 3.0T (Philips Medical Systems Inc). The hydrography sequences for MRC included 3D-SPACE (three-dimensional sampling perfection with application-optimized contrasts using different flipangle evolutions) with the following imaging parameters: TR/ TE1000-1200ms/131-264ms, matrix 384X384-320X320, pixel: 0.5X0.5; Nex:1.6-2, reconstructive slice thickness: $0.5-1.0 \mathrm{~mm}$, and 3D-Drive (three-dimensional driven equilibrium) with the following imaging parameters: TR/TE: 2000/200ms, matrix: 256X168, pixel: 0.6X0.6; Nex: 2, reconstructive slice thickness: $0.5-1.0 \mathrm{~mm}$. On image processing workstation, raw imaging data were used for oblique sagittal, coronal, or random orientation multi-planar reconstruction (MPR) according to the requirement of observers to determine the relationship between trigeminal nerve and vessels. In the analysis of the MRC image, the reversed gray scale technique was used so as to emphasize the image contrast. Image processing and analysis was carried out by two neurosurgeons and an experienced radiologist. The criteria to determine the responsible vessels for the trigeminal neurovascular compression were that the vessels were attached to the trigeminal nerve roots and resulted in the displacement of the nerve. In this series, 55 cases with trigeminal NVC, including 31 males and 24 females, age range 38-74 years with a mean age of 58.7 years, were demonstrated by MRC. According to the findings on MRC, neurovascular decompression surgeries were performed in 25 cases of them.

\section{RESULT}

75 cases $(51.4 \%)$ with trigeminal NVC, including 14 with bilateral and 61 with unilateral compression, were found in 146 cases. Among the unilateral cases, 26 cases were on the right side and 35 cases on the left side. Ipsilateral complex compressions by two different vessels were found in 5 cases, including 3 in the left side and 2 in the right. In total, 94 related vessels of trigeminal compression were discovered, including 57 (60.6\%) superior cerebellar arteries (SCAs), 19 (20.2\%) anterior inferior cerebellar arteries(AICAs), 5 (5.3\%) basilar arteries (BAs), 3 (3.2\%) vertebral arteries (VAs), 2 (2.1\%) posterior inferior cerebellar arteries (PICAs), and 8 $(8.5 \%)$ uncertain vessels in which the source could not be determined (Table I).

The anatomic basis for SCA resulting in trigeminal NVC is that its anterior pontomesencephalic segment and lateral pontomesencephalic segment frequently bend down to touch the trigeminal nerve root. Of 57 SCAs compression, 3 touched the upside of the trigeminal nerve and pressed it inferiorly. The others embedded into the area between trigeminal nerve root and brain stem, and pressed the inner side of the nerve pushing it outwards. As a result, the contact sites of trigeminal nerve root went through series of significant morphologic changes including concave, thinning and displacement (Figures 1 AB, 2 AB, 3 ABC). 49 SCAs' sites pressing trigeminal nerve root were discovered, including main trunks in 21, bifurcations in 4, caudal branches in 17 , and rostral combined with caudal branches in 7 . For the other 8 SCAs, whether their exact anatomic contact sites located in the trunk or branches were uncertain. The offended sites of trigeminal nerve root by SCA included root entry zone (REZ) in 36, porus entry zone (PEZ) in 11 and preganglionie segment (PGS) in 10.

Compression of the AICA was identified as the vessel trunk bending upwards to contact the ipsilateral trigeminal nerve root. Of all 19 cases related to AICAs, 18 ones protruded into the interval between the trigeminal nerve and brain stem. There were 14 cases with REZ compression, 2 cases with PEZ and PGS respectively, causing thinning, concave and outward shifting of contact sites (Figure 4 A,B,C). One AICA got to the lateral border of the trigeminal nerve and pressed its PGS. In these cases, the junctions of the trigeminal nerve and brain stem were at a lower position, which were almost at the middle plane of internal auditory canal. On the oblique sagittal MPR, steeper pathway of the nerve from brain stem to meckel's cavity could be seen clearly.

Tortuous and enlarged 3 VAs and 5 BAs with raised junction of bilateral VAs protruded superiorly into the inner side of trigeminal nerve. As a result, the nerves were pushed laterally and upwardly, causing their displacement and thinning (Figure $5 \mathrm{~A}, \mathrm{~B}$ ). Adjacent to the contact sites, there were 6 arteries at REZ and PGS, and 2 arteries at PEZ. In these patients, the compression of ipsilateral CN-VIII and CN-IX were found simultaneously. In one case associated with CN-VIII and $\mathrm{CN}-\mathrm{IX}$ compression by VA, the enlarged lumen with the mural thrombus was found.

PICA's compressions were seen in two cases with distorted $\mathrm{BA} / \mathrm{VAs}$. The raised VAs caused elevation of PICAs, which

Table I: Related Vessels of Trigeminal Compression in 75 Cases

\begin{tabular}{|l|c|}
\hline Vessels & Numbers \\
\hline SCA & $57(60.6 \%)$ \\
$\quad$ Trunk & $21(36.8)$ \\
Bifurcation & $4(7.0)$ \\
Caudal Br. & $17(29.8)$ \\
Rostral+ Caudal Br. & $7(12.3)$ \\
$\quad$ uncertain & $8(14.0)$ \\
\hline AICA & $19(20.2 \%)$ \\
VA & $3(3.2 \%)$ \\
\hline BA & $5(5.3 \%)$ \\
PACA & $2(2.1 \%)$ \\
Unkown & $8(8.5 \%)$ \\
\hline total & 94 \\
\hline
\end{tabular}



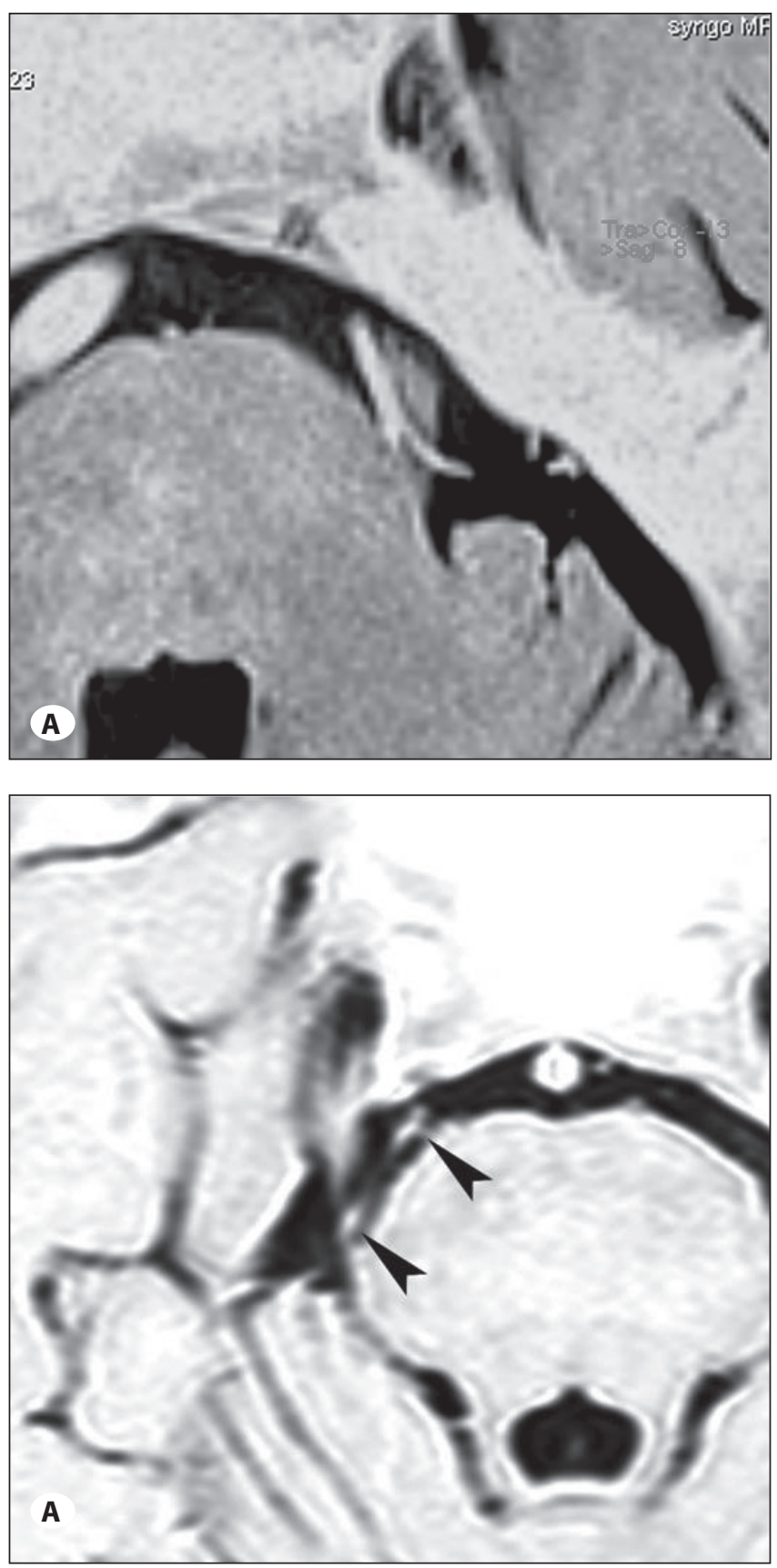

pushed the bottom of the PGS upwards. In 8 cases with trigeminal compression caused by uncertain vessels, all the offended sites of the trigeminal nerve root were at REZ. For the 5 patients with ipsilateral complex compression by multivessels, the related arteries were demonstrated as SCA plus AICA in 4 cases, and SCA plus BA in 1 case (Figure $6 A, B, C$ ).

In our series, the compressed sites of trigeminal nerve root were REZ (61.7\%), PGS (16\%), PEZ (16\%), and REZ + PGS (6.3\%) (Table II). In the 25 cases who had underwent microvascular decompression, the uncertain related vessels of 5 cases on MRC were confirmed as petrosal vein's branch surgically.

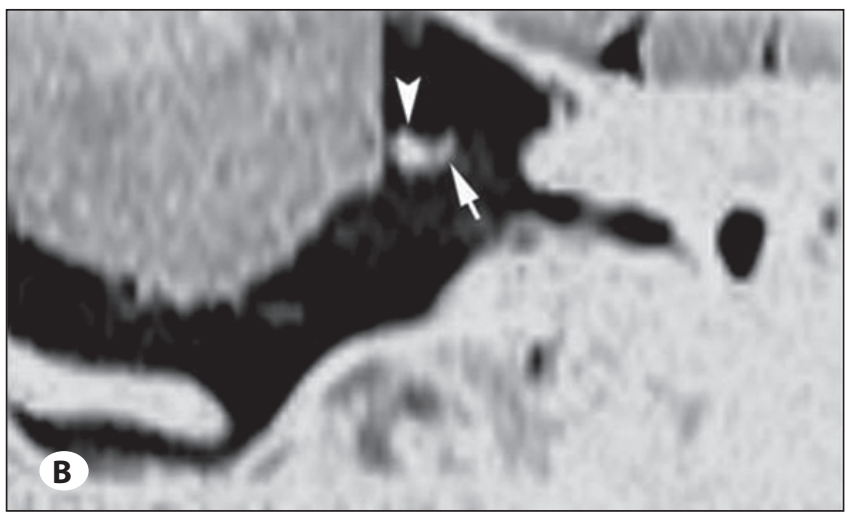

Figure 1: (A) Axial 3D-SPACE MR image. Left SCA main trunk with its bifurcation pressing the upper side of trigeminal nerve was showed. (B) Coronal multi-planar reconstruction (MPR). The fact that left SCA main trunk(arrow head) pressing trigeminal nerve root (arrow) was demonstrated.

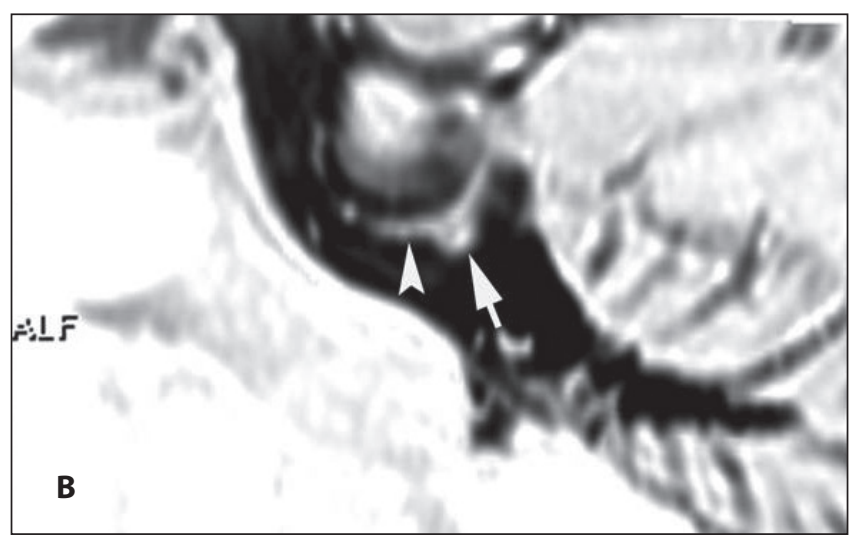

Figure 2: The trunk of right SCA pressing REZ of ipsilateral trigeminal nerve. (A) Axial 3D-DRIVE MR image. The two dots between right trigeminal nerve and pons suggested the curve trunk of SCA (arrow head) protruding into the interval and pressing REZ of right trigeminal nerve. (B) Oblique sagittal multiplanar reconstruction (MPR). Curve trunk of SCA (arrow head) running downward and pressing the upper side of trigeminal nerve (arrow) was demonstrated definitely.

In the other 20 cases, surgical finding was consistent with radiological diagnosis of NVC. However, 3 of them were still with concomitant compression by petrosal vein's branches, which were not diagnosed accurately on MRC.

\section{DISCUSSION}

Compression of trigeminal nerve root by vessels in cerebellopontine angle (CPA) is the common cause of trigeminal neuralgia $(1,3,4,7,20,23,24)$. The main related arteries includes SCA, AICA, BA, VA and pontine artery (PA) $(5,11,21)$. Imaging is the most effective means to diagnose NVC so far. Among the current imaging examination, MRI no 

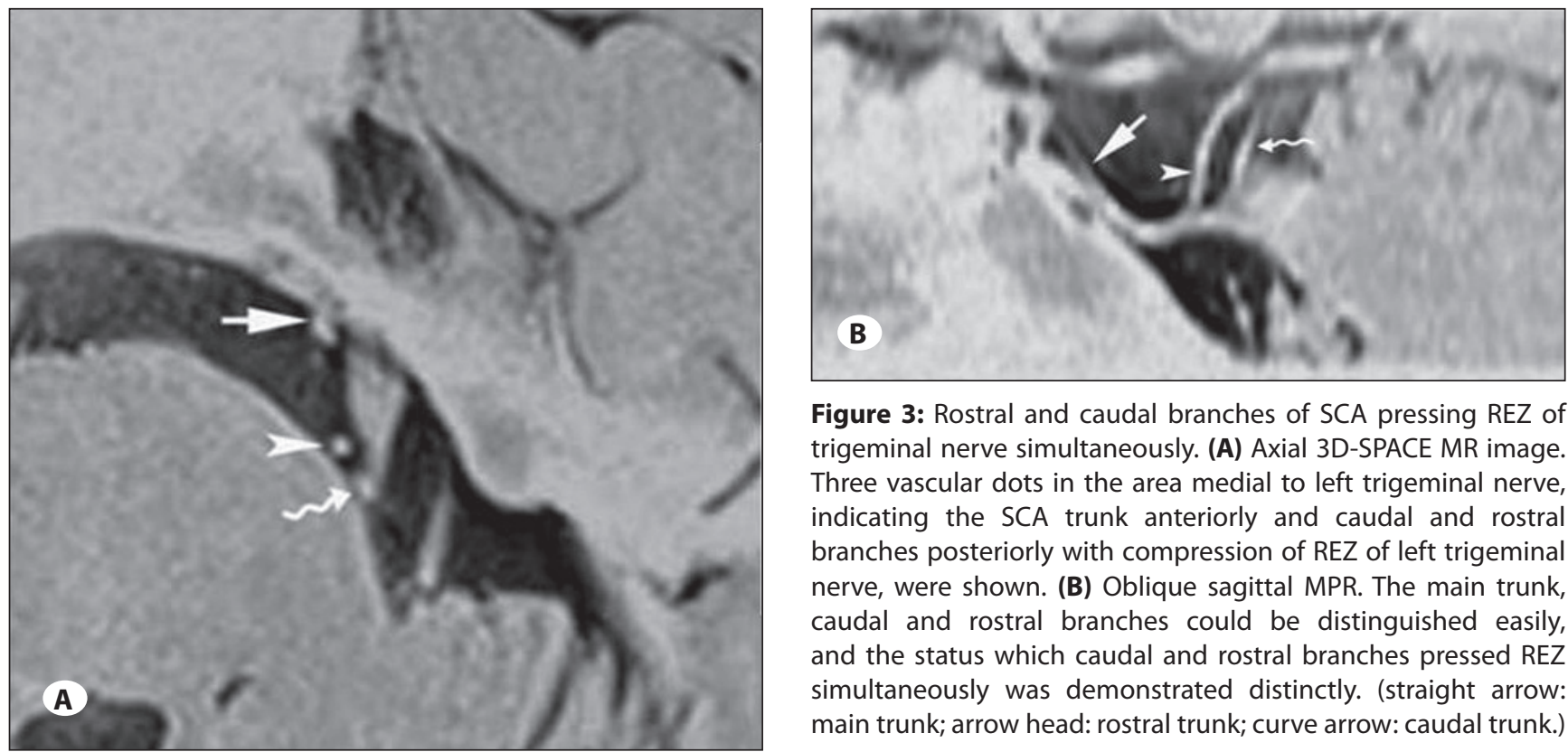

Figure 3: Rostral and caudal branches of SCA pressing REZ of trigeminal nerve simultaneously. (A) Axial 3D-SPACE MR image. Three vascular dots in the area medial to left trigeminal nerve, indicating the SCA trunk anteriorly and caudal and rostral branches posteriorly with compression of REZ of left trigeminal nerve, were shown. (B) Oblique sagittal MPR. The main trunk, caudal and rostral branches could be distinguished easily, and the status which caudal and rostral branches pressed REZ simultaneously was demonstrated distinctly. (straight arrow: main trunk; arrow head: rostral trunk; curve arrow: caudal trunk.)

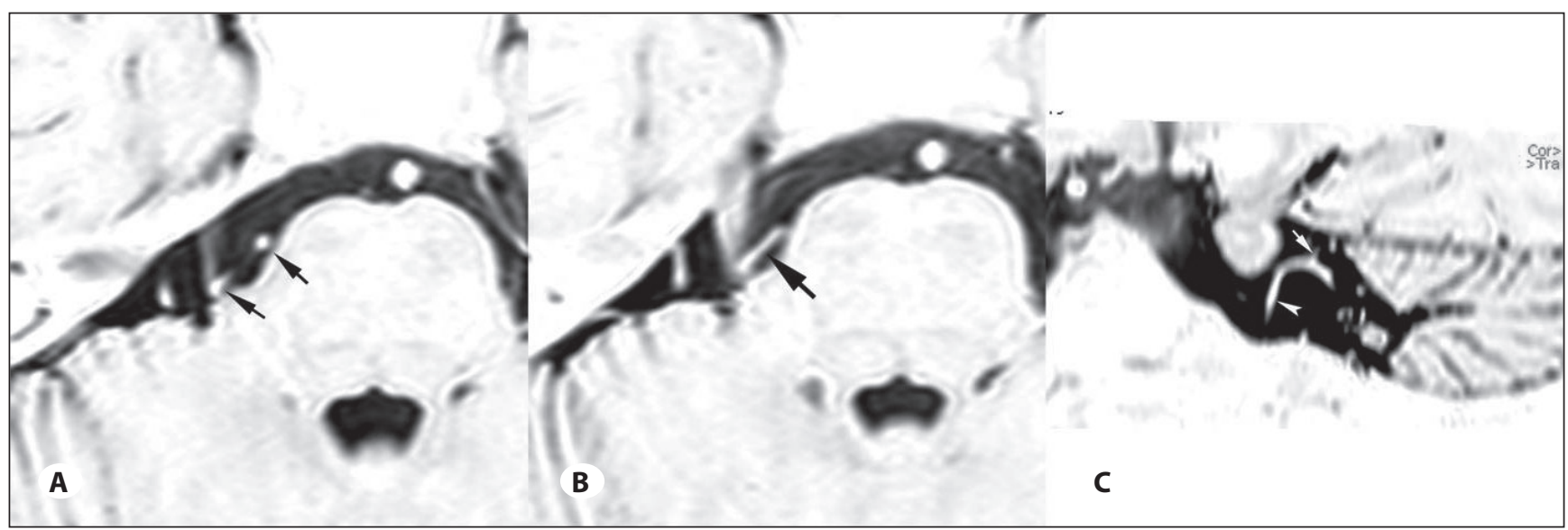

Figure 4: Right AICA pressing right trigeminal nerve. (A, B) Axial 3D-DRIVE MR image from lower to higher section. Two dots and short line (black arrow) with the concaved adjacent REZ of right trigeminal nerve in the interval indicated a fact that a vessel protruded into axilla of right trigeminal nerve root and pressed it. (C) Oblique sagittal MPR. The status was demonstrated that the vessel located beneath the trigeminal nerve and ran upward to form a convexity pressing the nerve (arrow). The follow trail of the vessel pointed out that it was AICA (arrow head).
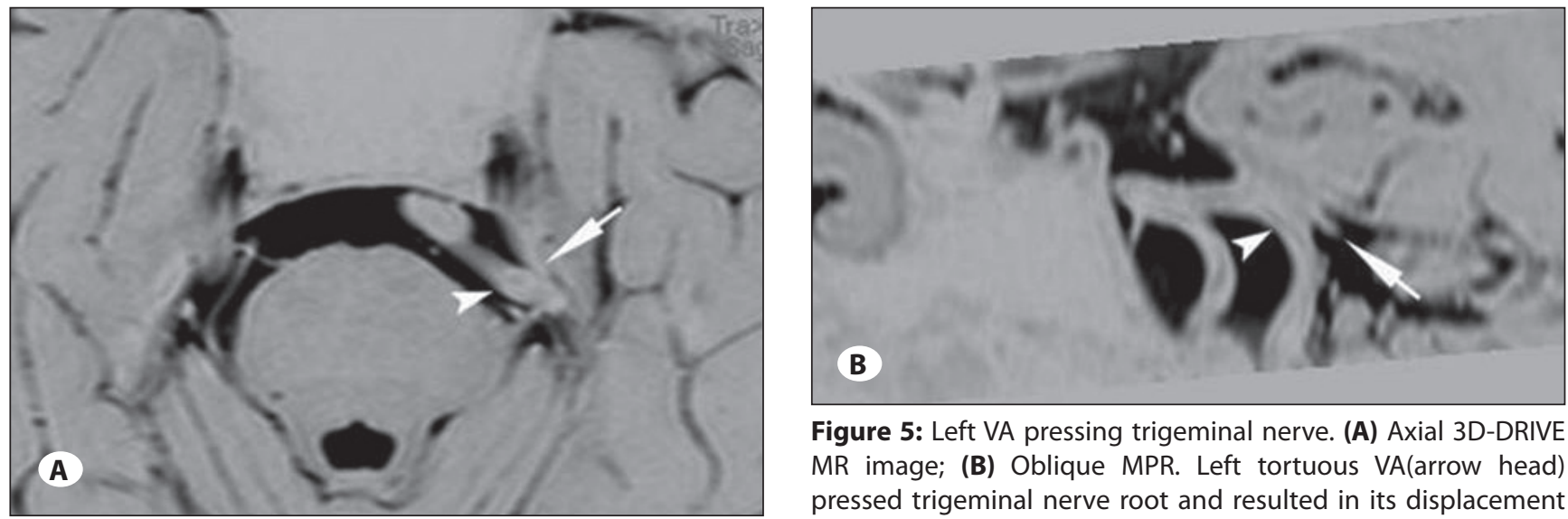

Figure 5: Left VA pressing trigeminal nerve. (A) Axial 3D-DRIVE MR image; (B) Oblique MPR. Left tortuous VA(arrow head) pressed trigeminal nerve root and resulted in its displacement and thinning (arrow). 


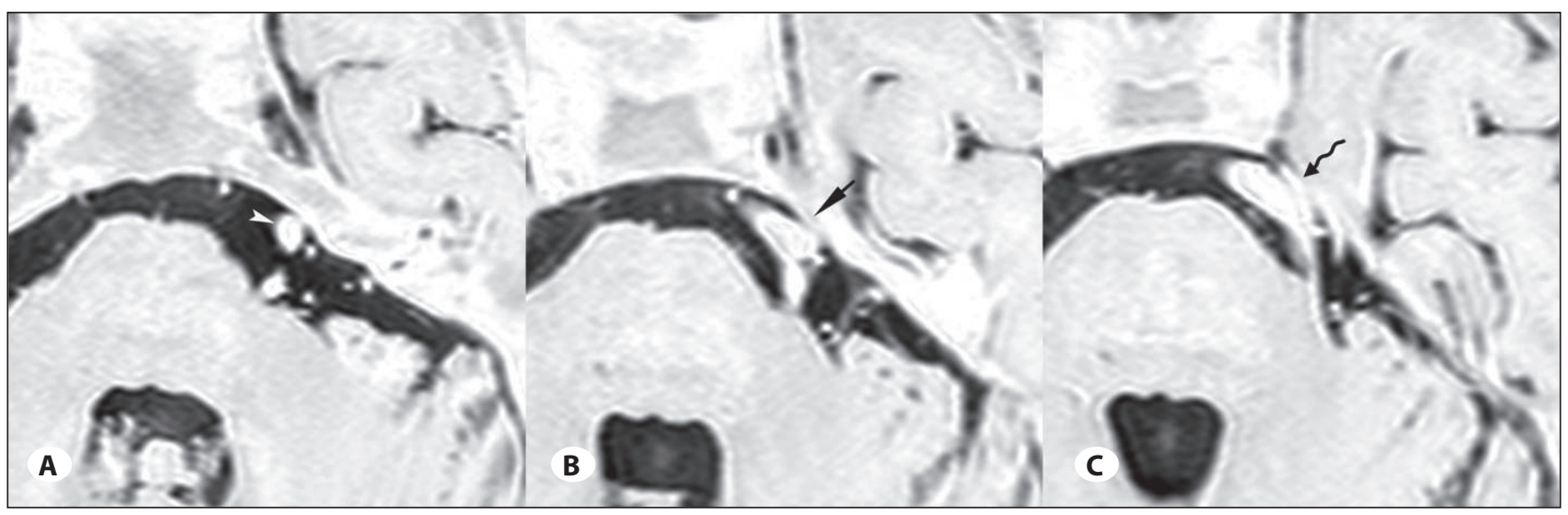

Figure 6: Complex trigeminal compression by BA and SCA. (A, B) Axial 3D-DRIVE MR image from lower to higher sections. The right VA (arrow head) run to left side tortuously and joined the left one to form conjunction of basilar artery which pressed left trigeminal nerve (arrow) and led to its displacement and atrophy. (C) Axial 3D-DRIVE MR image of slightly higher section than B. Main trunk and its bifurcation of SCA (curve arrow) pressing trigeminal nerve simultaneously were displayed distinctly.

Table II: Sites of Trigeminal Compression by 94 Related Vessels

\begin{tabular}{|l|c|c|c|c|c|}
\hline & REZ & REZ+PGS & PGS & PEZ & Total \\
\hline SCA & 36 & & 10 & 11 & 2 \\
\hline AICA & 14 & & 3 & 2 & 8 \\
\hline BA+VA & & 6 & 2 & & 2 \\
\hline PICA & & & & & 8 \\
\hline Unkonw & 8 & $6(6.3 \%)$ & $15(16 \%)$ & $15(16 \%)$ & 94 \\
\hline
\end{tabular}

doubt is the most valuable one. On conventional T2WI, with high signal of cerebrospinal fluid, the trigeminal nerve root and nearby vessels could be displayed contrastively. However, due to its unsatisfied definition and resolution, conventional MRI is difficult to accurately determine their relationships. With the help of high-resolution and heavy T2WI technology, MRC increases the contrast between cerebrospinal fluid and non-liquid substances by suppressing the background signal. As a result, it significantly improves the resolution of nerves and vessels in the posterior cranial fossa $(19,23)$. Compared with the conventional T2WI, MRC has more advantages in displaying NVC, and it provides valuable information for treatment protocols of micro-neurosurgery on trigeminal neuralgia $(2,8,9,13,14,16,18,20)$.

\section{The common arteries compressing trigeminal nerve root in CPA}

\section{Superior cerebellar artery (SCA)}

As one of the important arteries in the posterior fossa, SCA has close relation with $\mathrm{CN}-\mathrm{III}, \mathrm{CN}-\mathrm{IV}, \mathrm{CN}-\mathrm{V}$. Of the offending vessels to trigeminal nerve root, SCA accounts for the largest proportion, which was $78 \%$ reported by Ueda $F,(22)$ and $60.6 \%$ in our series. SCA originates from the basilar artery going posteriorly to supply the cerebellum and brain stem. On the basis of the course, it can be divided into four segments as follow: the segment anterior to midbrain (S1), the segment lateral to midbrain (S2), the segment intra-fissure between cerebellum and midbrain (S3) and segment on cerebellar cortex (S4). The trunk of SCA divides into caudal and rostral branches on its travelling, and its bifurcation might locate at the medial, lateral or upper side of trigeminal nerve root. Before the artery moves into lateral midbrain-cerebellar fissure, S1 and S2 frequently bend down as shallow curve. Once the degree of the curve goes deep enough to offend the upside of trigeminal nerve root or protruding into the axilla (ie, the area between the trigeminal nerve root and brain stem), the trigeminal compression could be evoked. In that case, the trigeminal nerve root is usually pressed downwards or pushed outwards. The location of the bifurcation of the trunk has certain influences on trigeminal nerve compression. If the bifurcation or trunk offends the nerve, due to its thicker diameter, the compression could be severer. When the caudal or rostral branch presses, the degree of compression could be relatively slight due to their smaller diameter. In this group of cases, the compression caused by trunk and the bifurcation takes the largest proportion (25/57).

\section{Anterior inferior cerebellar artery (AICA)}

AICA belongs to the middle neurovascular group in posterior fossa, under the trigeminal nerve, closely related with $\mathrm{CN}-\mathrm{VI}$, VII, VIII. If the anterolateral segment of AICA bends upward, 
it may touch the trigeminal nerve. At the same time, once the location of the trigeminal nerve root is relatively lower, the trigeminal NVC by AICA is more likely. In our series, compression caused by AICA took the second place. AICA ran upward to protrude into the axilla of the trigeminal nerve root to press it, and our finding is consistent with literatures. (12) However, the contact or compression may also occur at nerve's lateral side, as we found in one case of this group.

\section{Basilar artery (BA), Vertebral artery (VA) and Posterior inferior cerebellar artery (PICA)}

In the case of cerebral arteriosclerosis, enlargement and tortuosity of vertebral or basilar artery are very common. This change is often accompanied by the elevation of bilateral VAs and their conjunction, resulting in the compression of related cranial nerves, including CN-V, VI, VII, VIII and XI. That occurs more common in hypertensive and elderly patients. In our group, the ages of all these patients were over 60-years old. Raised vertebral or basilar artery distorted to enter the medial side of trigeminal nerve, and pressed the nerve outwards and upwards. As the basilar and vertebral arteries have larger caliber and stronger pulse, the degree of displacement of nerve is usually more serious, also atrophy of the nerve is more obvious compared with that pressed by SCA or AICA. All these signs above occur in all of our 8 patients.

The compression of trigeminal nerve caused by PICA is quite rare. This happening is frequently with raising of VA. In our series, we found this situation in 2 cases. On MRC, PICA is displayed as a vascular shadow close to the nerve. To determine it, we also need to understand its relationship with the vertebral artery on oblique coronal and sagittal images.

\section{Pontine artery (PA)}

Pontine artery is the relatively smaller artery which may bend upward to enter the medial side of trigeminal nerve, causing neural compression, similar to the AICA's offending. Continuously tracking its course on MRC is very helpful for distinguishing PA from AICA.

Consistent with the literature (12), we found that $61.7 \%$ of related arteries, including SCA, AICA, BA, and VA, mainly as a form of curve went into the axilla to press the nerve. The axilla of trigeminal nerve belongs to REZ where trigeminal nerve root transits from brain stem. The sheath of this section is possibly incomplete, maybe that is the reason why the vascular compression in this region is more common in patients with trigeminal neuralgia (15). In our study, we noted that the symptoms of the patients who suffered the vascular compression at PGS were less serious. This may suggest that the myelination of the trigeminal nerve have close relation with clinical symptoms of NVC. José GL found that the pressed site at the axilla of the trigeminal nerve often had short distance of about $3 \mathrm{~mm}$ from the brain stem (6). Based on preoperative imaging and intraoperative observation, we also confirmed that, either SCA or AICA, the touch site had a short distance from the trigeminal-brainstem junction, indicating good consistency between the MRC findings and surgical discovery. As to BAs/VAs, due to their larger caliber, they often oppress REZ and PGS simultaneously, as we found in 6 patients.

\section{Trigeminal NVC: Diagnostic criteria and advantages of 3D-MRC}

The trigeminal nerves always have close relationship with adjacent vessels. However, not all the people with neurovascular contact on trigeminal nerve have trigeminal neuralgia $(17,20)$. Therefore, to judge whether the adjacent vessel causes NVC on trigeminal nerve, we think that clinical symptoms of the neuralgia on trigeminal nerve distribution associated with imaging manifestations simultaneously such as thinning, atrophy or displacement of touch site of trigeminal nerve on MRC, should be considered as the conclusive evidence of trigeminal nerve-vascular compression.

Because the T2WI of conventional MRI has wide slice thickness, layer gap and unsatisfied contrast, it has some limitations on displaying the relationship between the trigeminal nerve root and adjacent vessels (23). Compared with conventional MRI, MRA has obvious advantages in showing related vessels, however its contrast between cistern signal and nerve signal is still unsatisfied. By increasing CSF signal and depressing the background tissue signal, the MRC improves the contrast between cerebrospinal fluid and adjacent structures so that the clarity of nerve and blood vessels is significantly increased, and the accuracy and sensitivity exploring their relationship are greatly improved (21). After obtaining the raw data, 3D-MRC could use MPR, virtual endoscopy (VE) or other post-processing techniques at workstation to get stereoscopic and realistic images to diagnose trigeminal NVC. In our group, related arteries visualized on MRC were all confirmed operatively in 25 patients who underwent surgical treatment, thus indicating high diagnostic accuracy of MRC.

\section{The clinical values and limitations of 3D-MPC for trigeminal NVC}

Compression caused by single vessel is common resulted from SCA or AICA. The curve of SCA or AICA, protruding into the axilla of the trigeminal nerve root, appears as two small dot-like shadows on axial image, representing the crosssection of its ascending and descending branch. According to our experience, on oblique sagittal MPR, the vascular curve above trigeminal nerve is more likely SCA's, while the one below the nerve is likely AICA's. Using MPR, we could explore vascular continuous courses to judge its relationship with basilar artery. This will provide some useful guidance for the design of operation protocol.

To SCA compression, as we discussed above, the relative position of SCA's bifurcation has clinical significance on the severity of trigeminal compression. MPR could help us display the site of SCA's bifurcation definitely.

The cause of trigeminal compression by AICA ascribes not only to its high position of the initial point of AICA from the basilar artery, but also to the lower position of the junction of trigeminal nerve and brainstem. In our group, lots of patients 
were found in such situation. Those junctions of nerve and brainstem were displayed on the plane of internal auditory meatus, suggesting that acoustic nerve was close to the trigeminal nerve. Exploring this on MRC is very necessary for preoperative formulation to protect acoustic nerve.

When the enlarged and twisted BA or VA offends trigeminal nerve, 3D-MPR is very useful to display the thinning and displacement of the trigeminal nerve root by comparing the contralateral one. Once bilateral VAs elevate and twist to one side, we should carefully analyze which VA leads to the compression, because possibly the related artery is from the opposite side. In addition, the basilar artery and vertebral artery may also press the glossopharyngeal nerve, facial nerve and vestibulocochlear nerve at the same time. Combined with clinical presentation, neurovascular decompression surgery of multi-cranial nerves could be considered preoperatively by virtue of 3D-MPR.

While unilateral side of the trigeminal nerve is pressed by mutli-vessels simultaneously, finding out the related vessels before operation is quite necessary. Especially when an enlarged BA or VA associated with a small vessel push the trigeminal nerve seriously, the small one is possibly likely to be ignored so that the decompression may not be operated thoroughly. MPR is very useful for showing these complex compressions. Using axial, coronal and oblique sagittal reconstruction along the direction of the nerve and vessel, it is not difficult to explore the pressed site of trigeminal nerve and discover the number of related vessels. Among our patients, we found a case with complex compression by BA and an inconspicuous SCA on MPR. This compression by combined cryptical SCA was confirmed in surgery.

Moreover, to micro-neurosurgery, subarachnoid width of CPA have a significant impact on the exposure of the operative field and surgical operations, therefore preoperative understanding is very important. MRC has obvious advantages in displaying cerebral cistern size. Conventionally, CPA cistern will widen as the age increases, that is to say, the width of CPA cistern in the elder is wider than that in the young. Some people's CPA cistern are congenital narrower than their peers, as we found in two cases. On MRC, neurosurgeons are able to get such information preoperatively in case the nerves and vessels are damaged by excessive traction.

Although MRC has prominent advantages in displaying NVC in patients with trigeminal neuralgia, we still found its some limitations compared with surgical confirmation in the following aspects.

1. In case of complex compressions by multi-vessels, the related vessel causing trigeminal neuralgia could not be determined sometimes. Especially with concurrent compression by branch of petrosal vein, MRC often could not judge it accurately, as 3 cases in our group. Moreover, simplex compression by the petrosal vein might be inaccurately diagnosed by MRC once in a while, and here we found 5 cases in such situation. This indicates that only using MRC to distinguish SCA or AICA from petrosal vein has considerable limitation.
2. The width of the CPA cistern has an impact on exploring relationship between nerves and vessels on MRC. To certain patients, their CPA cisterns are too narrow to determine the related vessels and track their sources.

Because arteries are presented as high signal intensity while veins are low signal intensity during the arterial phase on MRA, these imaging signs may help us distinguish veins from arteries among the liable vessels $(10,23)$. As MRA possesses advantages on displaying the arteries but not good on showing the cranial nerves, we suggest that, if possible, MRC and MRA should be performed at the same time for the patients with trigeminal neuralgia. It may be helpful in determining trigeminal NVC, clearing related vessels and increasing the accuracy of imaging diagnosis.

\section{CONCLUSION}

As we discussed above, there is no causal relationship between the neurovascular contact and trigeminal neuralgia. Therefore combination of clinical symptoms and imaging findings is very important to correct diagnosis of trigeminal NVC. To the patients suffering trigeminal neuroglia, the status of ipsilateral trigeminal nerve touched by vessels, including thinning, atrophy and displacement on image, should be determined as the conclusive evidence of trigeminal NVC. In terms of judging NVC, finding out the number and the origin of the related vessels, observing the change and contact site of involved nerve, as well as displaying the width of CPA cistern, 3D-MRC provides valuable information for neurosurgeons to plan the proper treatment regimen. However, the MRC still has certain limitations in identifying veins. In case of uncertain vascular origin or nature on MRC, we recommend performing MRA to help determining related vessels and improving diagnostic accuracy.

\section{REFERENCES}

1. Barker FG, Janetta PJ, Bissonette DJ, Larkins MV, Jho HD: The long-term outcome of microvascular decompression for trigeminal neuralgia. New England Journal of Medicine 334:1077-1083, 1996

2. Boecher-Schwarz HG, Bruehl K, Kessel G, Guenthner M, Perneczky A, Stoeter P: Sensitivity and specificity of MRA in the diagnosis of neurovascular compression in patients with trigeminal neuralgia: A correlation of MRA and surgical findings. Neuroradiology 40:88-95, 1998

3. Bowsher D, Miles J, Haggett C, Eldridge P: Trigeminal neuralgia: A quantitative sensory perception threshold study in patients who had not undergone invasive procedures. Journal of Neurosurgery 86:190-192, 1997

4. Jannetta PJ: Arterial compression of the trigeminal nerve at the pons in patients with trigeminal neuralgia. Journal of Neurosurgery 26 (Suppl):159-162, 1967

5. Jannetta PJ: Observations on the etiology of trigeminal neuralgia, hemifacial spasm, acoustic nerve dysfunction and glossopharyngeal neuralgia: Definitive microsurgical treatment and results in 117 patients. Neurochirurgia 20:145-154, 1977 
6. José GL, Nicolas Massager, Philippe D, Devriendt D, Desmedt F, Brotchi J, Levivier M: Neurovascular compression anatomy and pain outcome in patients with classic trigeminal neuralgia treated by radiosurgery. Neurosurgery 62:368-376, 2008

7. Kondo A: Follow-up results of microvascular decompression in trigeminal neuralgia and hemifacial spasm. Neurosurgery 40:46-51,1997

8. Kumon Y, Sasaki S, Kohno K, Ohta S, Ohue S, Miki H, Fukushima $\mathrm{T}$, Hanaksson S: Three-dimensional imaging for presentation of the causative vessels in patients with hemifacial spasm and trigeminal neuralgia. Surgical Neurology 47:178-184, 1997

9. Majoie CB, Hulsmans FJ, Verbeeten B Jr, Castelijns JA, van Beek EJ, Valk J, Bosch DA: Trigeminal neuralgia: Comparison of two MR imaging techniques in the demonstration of neurovascular contact. Radiology 204: 455-460, 1997

10. Patel NK, Aquilina K, Clarke Y, Renowden SA, Coakham HB: How accurate is magnetic resonance angiography in predicting neurovascular compression in patients with trigeminal neuralgia? A prospective, single-blinded comparative study. British Journal of Neurosurgery 17:60-64, 2003

11. Rhoton AL Jr: The cerebellopontine angle and posterior fossa cranial nerves by the retrosigmoid approach. Neurosurgery 47 Suppl 3:93-129, 2000

12. Rhoton AL Jr: Microsurgical anatomy of decompression operations on trigeminal nerve, in Rovit RL, Murali R, Jannetta PL (eds), Trigeminal Neuralgia. Baltimore: Williams \& Wilkins, 1990:165-200

13. Satoh T, Onoda K, Date I: Fusion imaging of three dimensional magnetic resonance cisternograms and angiograms for the assessment of microvascular decompression in patients with hemifacial spasms. Journal of Neurosurgery 106:82-89, 2007

14. Satoh T, Onoda K, Date I: Preoperative simulation for microvascular decompression in patients with idiopathic trigeminal neuralgia: Visualization with three-dimensional magnetic resonance cisternogram and angiogram fusion imaging. Neurosurgery 60:104-113, 2007

15. Seth L, Hilton DA, Coakham HB: Central demyelination of the $V$ th nerve root in trigeminal neuralgia associated with vascular compression. Brain Pathology 8:1-12, 1998
16. Sindou M, Leston J, Decullier E, Chapuis F: Microvascular decompression for primary trigeminal neuralgia: Longterm effectiveness and prognostic factors in a series of 362 consecutive patients with clear-cut neurovascular conflicts who underwent pure decompression. Journal of Neurosurgery 107:1144-1153, 2007

17. Tanaka T, Morimoto Y, Shiiba S, Sakamoto E, Kito S, Matsufuji $Y$, Nakanishi O, Ohba, T: Utility of magnetic resonance cisternography using three-dimensional fast asymmetric spin-echo sequences with multiplanar reconstruction: The evaluation of sites of neurovascular compression of the trigeminal nerve. Oral Surgery Oral Medicine Oral Pathology Oral Radiology and Endodontics 100:215-225, 2005

18. Tanrikulu L, Hastreiter P, Troescher-Weber R, Buchfelder M and Naraghi R: Intraoperative three-dimensional visualization in microvascular decompression. J Neurosurg 107:1137-1143, 2007

19. Tash RR, Sze G, Leslie DR: Trigeminal neuralgia: MR imaging features. Radiology 172:767-770, 1989

20. Tatsurou T, Eiji S, Shunji S, Masafumi O, Shinji K, Nao WS, Shinobu MT, Yoshiki I, Osamu N, Yasuhiro M: Relationship between the curative effects of carbamazepine administration and the neurovascular compression volume of the trigeminal nerve measured using magnetic resonance cisternography. Clinical Journal of Pain 25:753-759, 2009

21. Toru S, Keisuke O, Isao D: Preoperative simulation for microvascular decompression in patients with idiopathic trigeminal neuralgia: Visualization with three-dimensional magnetic resonance cisternogram and angiogram fusion imaging. Neurosurgery 60:104-114, 2007

22. Ueda F, Suzuki M, Fujinaga Y, Kadoya M, Takashima T: In vivo anatomical analysis of arterial contact with trigeminal nerve: Detection with three-dimensional spoiled grass image. British Journal of Radiology 72: 838-845, 1999

23. Valerie C, Phillip C, Michael A, David P, Gary M, Kim J: High-resolution three-dimensional magnetic resonance angiography and three-dimensional spoiled gradient-recalled imaging in the evaluation of neurovascular compression in patients with trigeminal neuralgia: A double-blind pilot study. Neurosurgery 58:666-673, 2006

24. Van Loveren H, Tew JM, Keller JT, Nurre MA: A 10-year experience in the treatment of trigeminal neuralgia. Journal of Neurosurgery 57:757-764, 1982 